\title{
Arabinase gene expression in Aspergillus niger: indications for coordinated regulation
}

\author{
Michel J. A. Flipphi, Jaap Visser, Peter van der Veen and \\ Leo $H$. de Graaff
}

\begin{abstract}
Author for correspondence: Leo H. de Graaff. Tel: +31 8370 84439. Fax: + 31837084011. e-mail: leo.degraaff@algemeen.mgim.wau.nl
\end{abstract}

Section Molecular Genetics of Industrial

Microorganisms,

Wageningen Agricultural

University, Dreijenlaan 2,

NL-6703 HA Wageningen,

The Netherlands

\begin{abstract}
Aspergillus niger secretes three glycosylated glycosyl hydrolases which are involved in degradation of the plant cell wall polysaccharide L-arabinan: $\alpha$-Larabinofuranosidases (ABF) A and B, and endo-1,5- $\alpha$-L-arabinase (ABN) A. The nucleotide sequence of the previously cloned gene encoding ABF A (abfA) from A. niger was determined. The coding region contains seven introns. Mature ABF A comprises 603 amino acids with a molecular mass of $65.4 \mathrm{kDa}$ as deduced from the nucleotide sequence. The secreted enzyme is $\mathbf{N}$-glycosylated. The primary structures of the three A. niger arabinases characterized lack similarity. Regulation of arabinase expression upon induction by sugar beet pulp and by L-arabitol was studied as a function of time. This was done in wildtype A. niger as well as in transformants carrying multiple copies of either one of the ABF-encoding genes. Each arabinase gene responded differently upon a mycelial transfer to L-arabitol-containing medium. Extra copies of abfA or abfB led to a decreased expression level of ABN A, though the repression elicited by abfB is stronger and more persistent than that effected by abfA. Multiple copies of both abf genes influence expression of the other ABF similarly, but to a far less pronounced degree than they affect ABN A synthesis. Four putative promoter elements, shared by all three arabinase genes, could be involved in coordination of L-arabinan degradation by $A$. niger.
\end{abstract}

Keywords: Aspergillus niger, $\alpha$-L-arabinofuranosidase, gene structure and regulation, endo-1,5- $\alpha$-L-arabinase, promoter elements

\section{INTRODUCTION}

Enzymes degrading L-arabinan, a branched polymer largely made up of $(1 \rightarrow 5)$-, $(1 \rightarrow 2)$ - and $(1 \rightarrow 3)$ - $\alpha$-linked $\mathrm{L}$-arabinofuranosyl residues, are commonly applied in structural studies of pectic and hemicellulosic plant cell wall heteropolysaccharides (e.g. Nishitani \& Nevins, 1989; Sakai \& Sakamoto, 1990; van de Vis et al., 1991; Will \& Dietrich, 1992; Lerouge et al., 1993). The results of such studies indicate that the L-arabinan component is involved in covalent cross-linking of cell wall polysaccharides. This has led to renewed interest in arabinases, with respect to their potential use in agro-industrial

\footnotetext{
Abbreviations: $A B F, \alpha$-L-arabinofuranosidase; $A B N$, endo-1,5- $\alpha$-L-arabinase; CNBr, cyanogen bromide; PNP-A, para-nitrophenyl $\alpha$-L-arabinofuranoside.

The GenBank accession number for the nucleotide sequence data reported in this paper is L.29005.
}

processes such as fruit juice technology, valorization of agricultural waste and bioconversion of plant biomass (cf. Whitaker, 1984; Voragen et al., 1987).

The hyphal fungus Aspergillus niger secretes an endo-1,5$\alpha$-L-arabinase (ABN A) (EC 3 2.1 .99) and two distinct $\alpha$ $\mathrm{L}$-arabinofuranosidases (ABF A and B) (EC 3.2.1.55) which are considered the main L-arabinan-degrading activities (Voragen et al., 1987; Rombouts et al., 1988; van der Veen et al., 1991). These glycosylated enzymes act synergistically in degrading branched L-arabinan: the preferred substrate for $A B N A$ is linear (debranched) $(1 \rightarrow 5)-\alpha$-L-arabinan, the backbone of the polymer, while the $\mathrm{ABFs}$ are typical glycosidases increasingly active against oligosaccharides of a lower degree of polymerization (Rombouts et al., 1988; McCleary, 1991; Beldman et al., 1993; Lerouge et al., 1993). Both ABFs are also involved in arabinoxylan degradation as debranching hydrolases, removing $\alpha$-linked L-arabinofuranosyl residues from wheat flour arabinoxylan fragments (Kor- 
melink et al., 1993). Previously we studied the production of the $A$. niger arabinases using enzyme-specific antisera (van der Veen et al., 1991, 1993). All three were found to be secreted when grown on plant cell wall fractions containing L-arabinan, e.g. sugar beet pulp. L-Arabitol, an intermediate of $A$. niger $\mathrm{L}$-arabinose catabolism (Witteveen et al., 1989), also mediates arabinase expression. Recently we cloned the three arabinase-encoding genes from $A$. niger and analysed the structure of two of these genes, $a b n A$ encoding $\mathrm{ABN} A$ and $a b f B$ encoding $\mathrm{ABF} \mathrm{B}$ (Flipphi et al., 1993a, b, c).

In this paper, arabinase expression induced by sugar beet pulp or L-arabitol has been studied as a function of time, both in wild-type $A$. niger and transformed $A$. niger strains containing multiple copies of either the $a b f A$ or the $a b f B$ gene. The nucleotide sequence of the abf $A$ gene encoding $\mathrm{ABF} A$ and its structure are presented. Upon comparison of the three $A$. niger arabinase genes, common sequence elements were identified which might be involved in regulation of arabinase gene expression.

\section{METHODS}

Escherichia coli strains and plasmids. E. coli $\mathrm{DH} 5 \alpha$ was used to generate and propagate plasmids; E. coli JM101 was used to generate recombinant $\mathrm{M} 13 \mathrm{mp} 18 / 19$ phages for sequencing. Plasmid vectors pEMBL (Dente \& Cortese, 1987) and p(jEM (Promega) were used in DNA subcloning. Plasmids pIM900, containing the $A$. niger abf $A$ gene, and $\mathrm{pC} 1 \mathrm{X} 1$, an abf $A$ cl)NA clone, were described previously (Flipphi et al., 1993c). Plasmids pIM950 and pIM991 contain the $A$. niger abn $A$ and $a b f B$ genes, respectively (Flipphi et al., 1993a, b). Plasmid pSF5, kindly provided by Dr J. R. Kinghorn, (Plant Molecular Genetics Unit, University of St Andrews, Scotland, UK), carries the $A$. nidulans gene encoding $\gamma$-actin described by Fidel et al. (1988). General DNA manipulations were performed according to Sambrook et al. (1989).

Aspergillus strains and growth conditions. A. niger $\mathrm{N} 402$ ( $\operatorname{csp} A 1$ ) originates from wild-type strain N400 (CBS 120.49) and is a morphological mutant with short conidiophores. Generation of $A$, niger $a b f A$ and $a b f B$ transformants was described previously (Flipphi et al., 1993a, c). Growth conditions and media used in cultivation were as described by Flipphi et al. (1993c), using $6 \mathrm{~g} \mathrm{NaNO}_{3} \mathrm{I}^{-1}$ instead of $\mathrm{NH}_{4} \mathrm{Cl}$ as the nitrogen source and $1 \%(\mathrm{w} / \mathrm{v})$ of the carbon source indicated. Transfer experiments were performed according to Flipphi $e t a l$. (1993b). L-Arabitol was obtained from Sigma. Sugar beet pulp, a gift from CSM (Breda, The Netherlands), was ground in a Waring blender prior to use.

Sequence determination and analysis. DNA fragments were cloned both in plasmid vectors (pEMBL, pGEM) and in M13mp18/19. DNA sequences were determined by the dideoxynucleotide chain-termination method (Sanger et al., 1977) using the T7 Sequencing Kit from Pharmacia LKB according to the supplier's instructions. Single-stranded M13 DNA as well as alkali-denatured plasmid DNA were used as template; both general sequencing primers and gene-specific oligonucleotides were employed as primers. All nucleotide sequences were determined on both strands. Computer analysis was done using the PC/GENE program (IntelliGenetics) and the sequence analysis software package of the Genetics Cornputer Group. Cyanogen bromide $(\mathrm{CNBr})$ cleavage of $\mathrm{ABF} A$ and amino acid sequence determination were performed as described previously (Flipphi et al., 1993b). The transcription initiation site was deduced upon primer extension mapping according to the method of Calzone $e t$ al. (1987) as described by Flipphi et al. (1993a). Poly A ${ }^{+}$RNA, isolated from $A$. niger abf $B$ transformant N593::pIM900-1 after $1 \mathrm{~h}$ of L-arabitol induction as described previously (Flipphi et al., 1993c), was used as template. The 17mer oligonucleotide which served as primer ( $5^{\prime}$ TGTTGCCGGCTGTCTGG $3^{\prime}$ ) is complementary to nucleotides -16 to +1 of the determined abf $A$ sequence, as shown in Fig. 2.

Enzymic deglycosylation. $N$-Linked carbohydrate moieties were removed from purified $A$. niger ABF A (van der Veen $e t$ al., $1991)$ with peptide- $N^{4}$-( $N$-acetyl- $\beta$-glucosaminyl $)$ asparagine amidase (EC 3.5.1.52), which cleaves off all three types of $N$ linked carbohydrate oligomers (Hirani et al., 1987; Tarentino \& Plummer, 1987). N-Glycanase from Genzyme was used according to the manufacturer's instructions. Protein was analysed by SDS-PAGE using $10 \%(\mathrm{w} / \mathrm{v})$ polyacrylamide gels containing $0 \cdot 1 \%(\mathrm{w} / \mathrm{v})$ SDS (Laemmli, 1970). Protein test mixture 4 (Serva) provided molecular mass markers. The gels were stained with Coomassie brilliant blue R250.

Determination of arabinase activity in culture medium. Medium samples were filtered over filter paper and centrifuged (3000 r.p.m., $15 \mathrm{~min}$ ) to pellet debris. ABF was assayed by measuring hydrolysis of para-nitrophenyl $\alpha$-L-arabinofuranoside (PNP-A) (Sigma) as described previously (van der Veen $e t$ al., 1991). ABN activity was determined using A rabinaZyme tablets (Megazyme) according to the manufacturer's instructions.

Isolation of RNA and genomic DNA. Mycelium was harvested from liquid cultures, washed with saline and powdered as described previously (Flipphi et al., 1993c). A. niger genomic DNA was isolated according to the method of de Graaff et al. (1988). Total RNA was isolated from the mycelial powder by guanidinium thiocyanate extraction (Chirgwin et al., 1979) and subsequent centrifugation over a $5.7 \mathrm{M} \mathrm{CsCl}$ cushion overnight at 32000 r.p.m. (Glišin et al., 1974). The quality of the RNA isolated was tested by native electrophoresis in $1 \%(\mathrm{w} / \mathrm{v})$ agarose in the presence of $25 \mu \mathrm{g}$ ethidium bromide $\mathrm{I}^{-1}$. The RNA concentration was calculated from $A_{260}$.

Slot blot analysis of RNA. Total RNA was denatured with glyoxal and dimethylsulfoxide according to McMaster \& Carmichael (1977). Denatured RNA samples were diluted in $10 \mathrm{mM}$ sodium phosphate buffer, $\mathrm{pH} 7 \cdot 0$. Either 5 or $1 \mu \mathrm{g}$ RNA was applied to each slot of a Hybri-Slot manifold (Gibco BRL), and was transferred to Hybond- $\mathrm{N}$ membrane (Amersham)

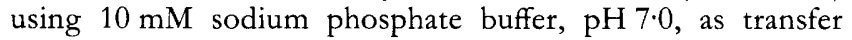
buffer. The RNA was fixed to the nylon support by baking at $80^{\circ} \mathrm{C}$. Prior to hybridization glyoxal was removed as indicated by Sambrook et al. (1989). The slot blots were probed with ${ }^{32} \mathrm{P}$ labelled DNA fragments specific for either one of the RNAs of interest using standard prehybridization and hybridization solutions containing $50 \%(\mathrm{v} / \mathrm{v})$ formamide (Merck) and $6 \times$ SSC at $42{ }^{\circ} \mathrm{C}$, essentially according to Sambrook et al. (1989) the hybridization solution, however, additionally contained $10 \%(\mathrm{w} / \mathrm{v})$ dextran sulphate (Pharmacia LKB) and $0 \cdot 1 \%$ $(\mathrm{w} / \mathrm{v})$ sodium pyrophosphate (Merck). Excess probe was removed by two sequential 20 min washing steps at $68{ }^{\circ} \mathrm{C}$ in $2 \times$ $\mathrm{SSC} / 0 \cdot 1 \%(\mathrm{w} / \mathrm{v})$ SDS $/ 0 \cdot 1 \%(\mathrm{w} / \mathrm{v})$ sodium pyrophosphate. The $A$. nidulans $\gamma$-actin gene was used as a probe to quantify the amount of constitutively expressed $\gamma$-actin mRNA, which served as a reference. Hybridization with the heterologous actin probe was carried out at $37 \cdot 1^{\circ} \mathrm{C}$ and washing was done at $60^{\circ} \mathrm{C}$, using the same buffers as for the homologous probes. 


\section{RESULTS}

\section{Primary structure of the abfA gene}

In a previous paper we reported the isolation of the $A$. niger abf $A$ gene and proved its identity by overexpression of $\mathrm{ABF}$ A by $A$. niger and $A$. nidulans transformants in which additional copies of the abf $A$ gene were introduced by co-transformation (Flipphi et al., 1993c). Fig. 1 shows the part of plasmid pIM900, which carries the cloned abf $A$ gene, from which the nucleotide sequence was determined. In addition, the $\mathrm{N}$-terminal amino acid sequences of purified $\mathrm{ABF} A$ and of a peptide derived from $\mathrm{ABF}$ A upon $\mathrm{CNBr}$ treatment, were determined. The sequence XXLKVXTQGG (10 residues) was found for the $\mathrm{N}$-terminus of $\mathrm{ABF} A$, while for the $\mathrm{N}$-terminus of the CNBr-generated peptide the sequence LQNPGLQGTAPXLTA (15 residues) was determined. Residues which could not be assigned are indicated as X.

The amino acid sequence data enabled us to deduce the position of the coding region of the abf $A$ gene within the determined DNA sequence, starting at position 1 and ending with a TAG stop codon situated at position 2237 (Fig. 2). The structural region contains several introns of which the two most 3 '-positioned (introns $F$ and $G$ ) were established by sequencing pC1X1, the cDNA clone used to isolate the abf $A$ gene (Flipphi et al., 1993c). Sequence analysis of a second $\mathrm{cDNA}$ clone (pC2X1-approximately $1.5 \mathrm{~kb}$ cDNA insert), isolated from the same cDNA library from which $\mathrm{pC} 1 \mathrm{X} 1$ originates, established introns $\mathrm{B}, \mathrm{C}, \mathrm{D}$ and $\mathrm{E}$ (results not shown). Intron $\mathrm{A}$ remains unestablished but its border sequences and the putative lariat formation site conform to the generally established consensus sequences proposed for introns of fungal genes (cf. Gurr et al., 1987; Rambosek \& Leach, 1987; Unkles, 1992). Moreover, it contains stop codons in all frames and removal of this $52 \mathrm{bp}$ sequence brings the two determined amino acid sequences within the same reading frame (Fig. 2).

The two isolated $\mathrm{cDNAs}$ differ with respect to the length of the $3^{\prime}$ non-coding sequence of the $a b f A$ transcript. The

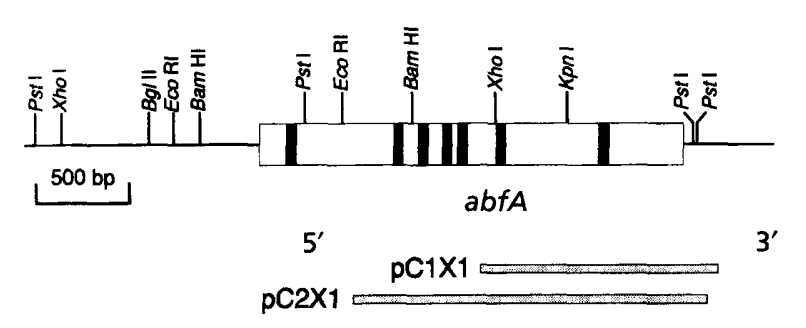

Fig. 1. Restriction map of the $3958 \mathrm{bp}$ fragment of p/M900 from which the DNA sequence is determined. The sites for Pstl, Xhol and Kpnl (cf. Flipphi et al., 1993c) as well as for BgllI, EcoRI and $B a m H I$ are indicated. The coding region of the abfA gene is represented by a box, the shaded areas mark the introns. Underneath, the orientation and extent of the CDNA inserts from $p C 1 \times 1$ and $p C 2 \times 1$ are indicated. Upon sequence analysis, pC1X1 turned out to be a hybrid clone containing two fused cDNAs (two polyA stretches) of which only the $5^{\prime}$ one (approximately $1.0 \mathrm{~kb}$ in length) is abfA-specific. ultimate $3^{\prime}$ abf $A$-specific base of $\mathrm{pC} 2 \mathrm{X} 1$ was found to correspond to the $\mathrm{C}$ at position 2371 (a non-coding sequence of $132 \mathrm{bp}$ ) and that of $\mathrm{pC} 1 \mathrm{X} 1$ to the $\mathrm{T}$ at position 2419 (a non-coding sequence of $180 \mathrm{bp}$ ). This strongly suggests the presence of (at least) two sites for polyadenylation. Upon primer extension mapping using L-arabitol-induced polyA ${ }^{+}$RNA from $A$. niger abf $A$ transformant N593::pIM900-1 as template (results not shown), we could identify a single site for transcription initiation at position -39 relative to the start codon.

\section{Deduced primary structure of ABF A}

Removal of the seven intron sequences from the coding region of abf $A$ leads to an open reading frame of $1884 \mathrm{bp}$ coding for a protein of 628 amino acids (Fig. 2). Within the deduced sequence of the primary gene product the determined N-terminal sequence of mature extracellular $\mathrm{ABF} A$ is preceded by a 25 residue-long sequence which could serve as a signal peptide for secretion. Small neutral amino acid residues are present at positions -3 (alanine) and -1 (glycine) relative to the proposed signal processing site, as predicted using the method described by von Heijne (1986). Mature ABF A consists of 603 amino acids with a deduced molecular mass of $65.4 \mathrm{kDa}$ and a theoretical isoelectric point of $3 \cdot 7$. These characteristics differ from those previously reported for the purified ABF A protein, where we found an apparent molecular mass of $83 \mathrm{kDa}$ and an isoelectric point of 3.3 (van der Veen et al., 1991). This discrepancy is likely to be due to carbohydrate moieties as ABF A is a glycoprotein (Voragen et al., 1987). The amino acid sequence reveals the presence of 10 putative sites for $N$-linked glycosylation (Fig. 2). Removal of $N$-linked oligosaccharides from purified ABF A with $\mathrm{N}$-glycanase resulted in a reduction of the apparent molecular mass of over $15 \%$, as determined upon SDSPAGE (Fig. 3). The apparent molecular mass of the deglycosylated protein $(68 \mathrm{kDa})$ is only slightly higher than the deduced molecular mass $(65 \cdot 4 \mathrm{kDa})$. Time course study of the deglycosylation (not shown) suggested that at least three $N$-linked oligosaccharides are present. One of these is highly resistant to enzymic hydrolysis, which leads to the minor band just above the main band present in lane 4 of Fig. 3.

\section{Comparison of ABF A with other glycosyl hydrolases}

The deduced amino acid sequence of $\mathrm{ABF} A$ does not show homology with the two other $A$. niger L-arabinandegrading enzymes, $\mathrm{ABF} B$ and $\mathrm{ABN} A$. $\mathrm{ABF} A$ and ABN A have one sequence EYGST/WII/DT/- $\mathrm{HT} /$ GST in common, in ABF A present at position 132-143 and in ABN A at position 106-116 (Flipphi et al., 1993b). No similarities were found upon comparison with three prokaryotic enzymes having ABF-like activities, i.e. two $\beta$-D-xylosidases exhibiting PNP-A-hydrolysing activity and an $\alpha$-L-arabinofuranohydrolase only acting on oat spelt xylan (Kellett et al., 1990; Utt et al., 1991; Sakka et al., 1993). Screening the major protein data libraries for similarity, however, resulted in the identification of several short, highly similar amino acid sequences (listed 


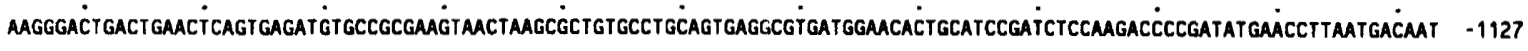

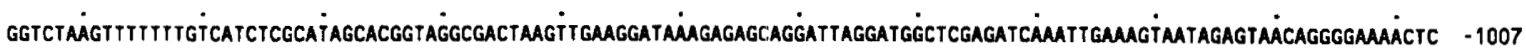

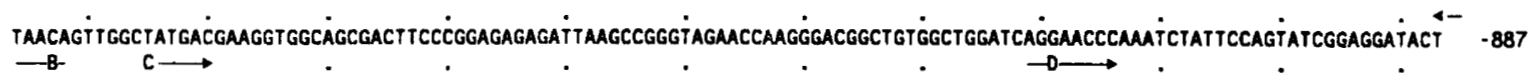

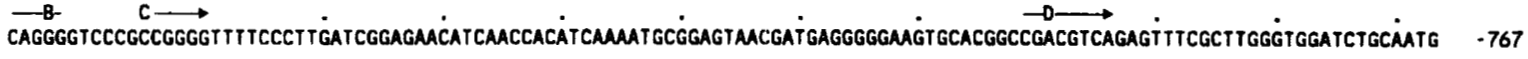

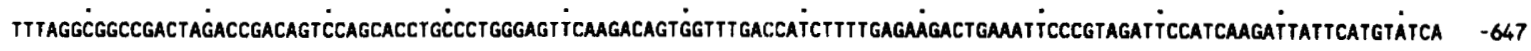

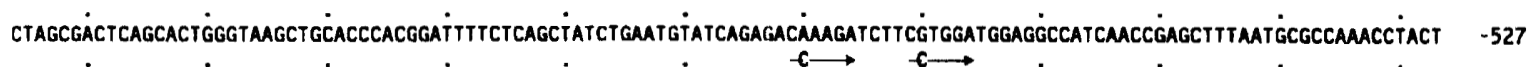

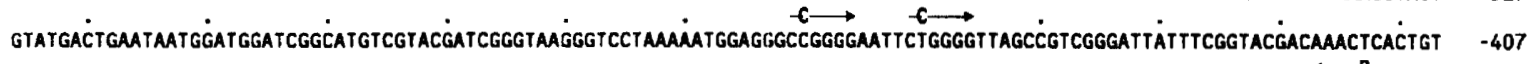
icactrigatctcggcgtggttgcggct

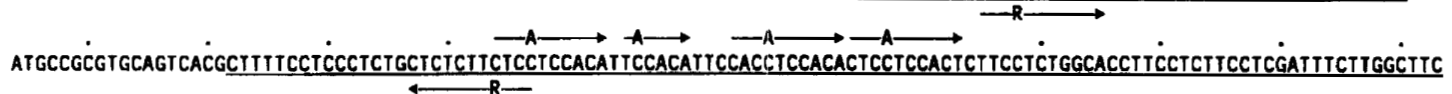
$\stackrel{\leftrightarrow}{\longleftarrow} \mathrm{R}-\mathrm{C}$.

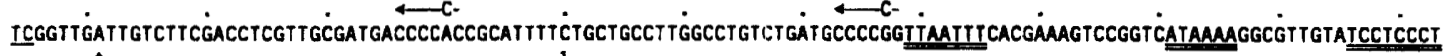
IIGCAACAATGACACCAGGCTCAGCTICCTCCAGACAGCCGGCAACATGGTGGCCTTTTCAGCTCITTCGGGCGTCAGCGCCGTTICTTIACTACTATCCCTCGTICMMATGCACACGG

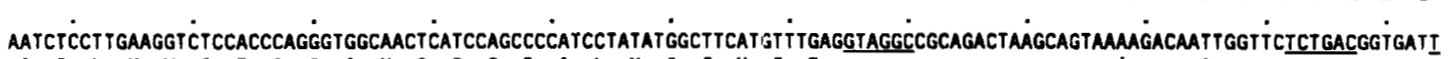

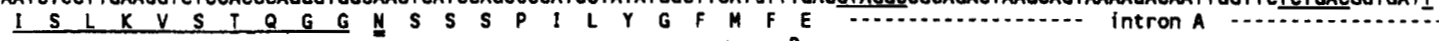

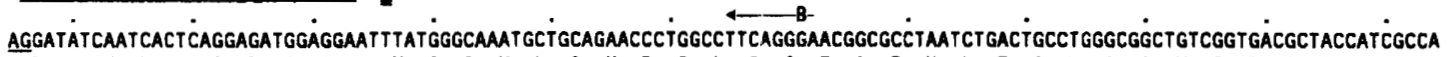
- D I N H S G D G G I Y G Q M L Q N P G L Q G T A P N L T A W A A V G D A T I A I

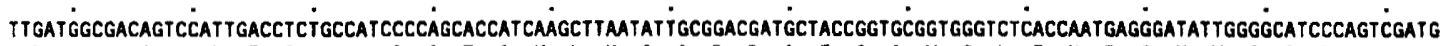
D G D S P L T S A I P S T I K L N I A D D A T G A V G L T N E G Y W G I P V D G

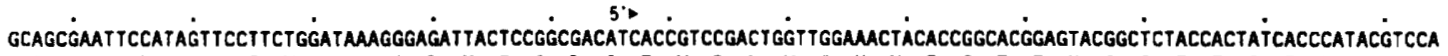
S E F H S S F W I K G D Y S G D I T V R L V G N Y T G T E Y G S T T I T H T S T

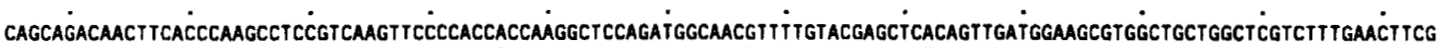
A D N F T Q A S V K F P T T K A P D G N V L Y E L T V D G S V A A G S S L N F G

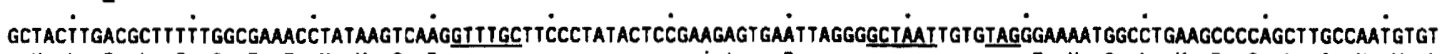
Y L T L F G E T Y K S R ............. intron B ...................

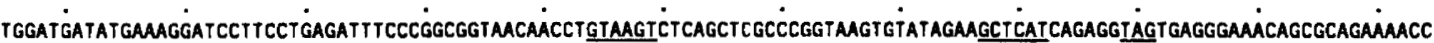
D D M K G S F L R F P G G N $L$.

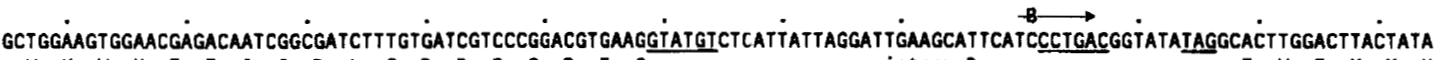
$W K W N E T I G D L C D R P G R E G$

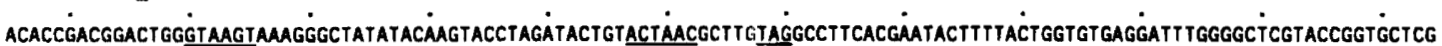

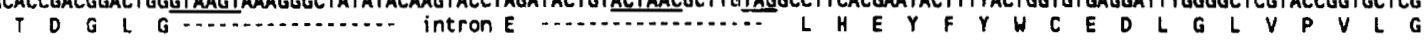

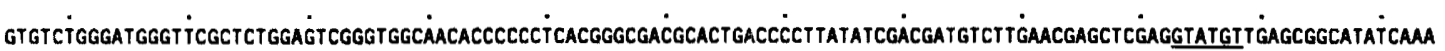

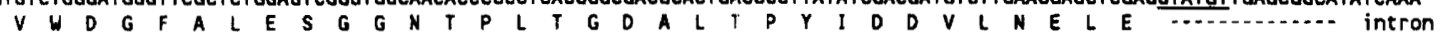
trgatagctgaagctäacccattggcagtacatctigggtgatacgagcacgacciatggagcgtggcgcgcgGcanacggacaggaggagccgtggaaccttaccatggtcgagattgg

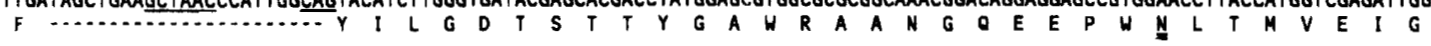

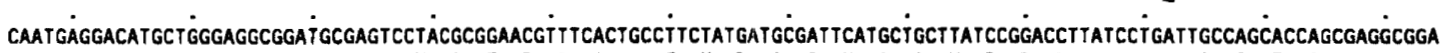
N E D M L G G G C E S Y A E R F T A F Y D A I H A A Y P D L I L I A S T S E A D

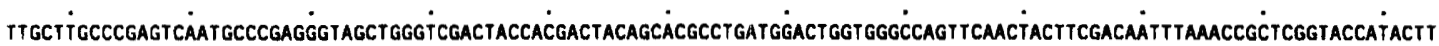
C L P E S M P E G S W V D Y H D Y S T P D G L V G O F N Y F D N L N R S V P Y F

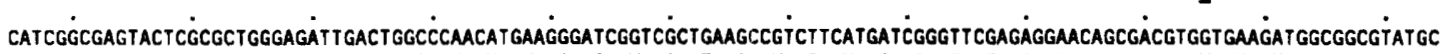
1 G E Y S R W E I D W P N M K G S A E A V F I G F E R N S D V V K M A A Y A

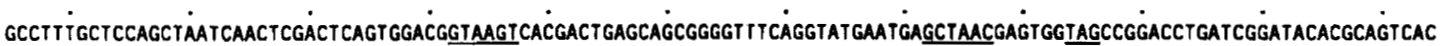

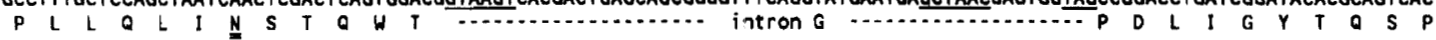

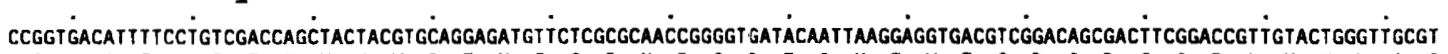
G D I F L S T S Y Y V Q E M F S R N R G O T I K E V T S D S D F G P L Y W V A S

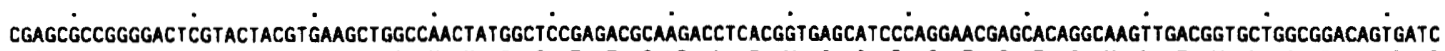
$S A G$ D S Y Y V K L A N Y G S E T Q D L T V S I P G T S T G K L T V L A D S D P CGGATGCGTATAACTCGgACACCCAGACGCTGGTCACGCCGAGTGAATCGACGgTGCAGGCGAGCAATGGCACTTITACCTTTAGTTTGCCGGCATGGGCGGTGGCTGTCCTGGCGGCGA D A Y N S D T Q T L V T P S E S T V O A S N G T F T F S L P A W A V A V L A A N actagcgt tgattggggcgagctcgtatgggcggcaagtcgaataitatctgcaggtgtggtgtcatgtactgcagtattrctgatitaacgatagagagatagatccatgctatatacct

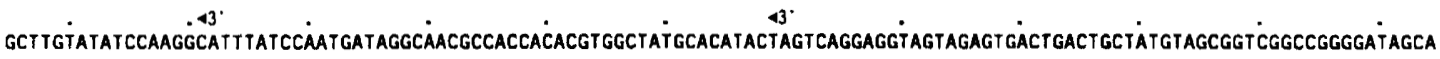
gtTGAi TGACCCCAATt

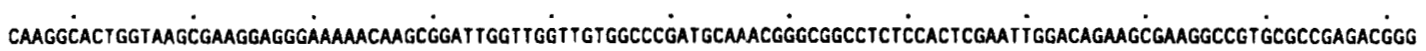


in Table 1) shared by ABF A and two strongly related Klebsiella pullulanases ( $\alpha$-dextrin endo-1,6- $\alpha$-glucosidase; EC 3.2.1.41) (Katsuragi et al., 1987; Kornacker \& Pugsley, 1989). Pullulanases belong to glycosyl hydrolase family 13 , which contains only $\alpha$-amylase-like hydrolases and transferases (Henrissat, 1991). Two of the sequences recognized overlap with homologous regions commonly found within $\alpha$-amylases (Melasniemi et al., 1990; Table 1). However, hydrophobic cluster analysis (cf. Gaboriaud et al., 1987) could not verify the similarities indicated by primary structure alignment.

\section{Study of arabinase expression in wild-type and transformant $\boldsymbol{A}$. niger strains}

As the three $A$. niger arabinases are involved in degradation of the same polysaccharide and their synthesis is simultaneously induced upon growth on polymeric substrates and L-arabitol (van der Veen et al., 1991, 1993), regulation of expression of the corresponding genes could well be coordinated. We have studied arabinase expression in $A$. niger wild-type $\mathrm{N} 402$ and in transformant strains containing additional copies of either the abf $A$ or the $a b f B$ gene. Several $a b f A$ and $a b f B$ transformants covering the available range from low to high copy numbers, as deduced from Southern blot analyses (results not shown), were selected.

The selected strains were grown submerged in liquid medium containing sugar beet pulp as the carbon source and $0.1 \%(\mathrm{w} / \mathrm{v})$ yeast extract to initiate efficient germination of the inoculum. Medium samples were taken at 24,36 and $48 \mathrm{~h}$ after inoculation, in which both the ABN activity and the PNP-A hydrolysing activity were measured (Table 2). This approach enabled us to monitor the effect of either $a b f$ gene on the expression of the $A B N$ A-encoding gene $(a b n A)$ with time. The activity assay for ABN is highly specific, while the PNP-A hydrolysing activity represents the combined activities of $A B F A$ and $A B F B$. In general, the levels of ABN activity produced by all abf transformants are progressively lower with increasing PNP-A hydrolysing activity. However, the reduction of the $\mathrm{ABN} A$ expression levels is rather correlated with the abf gene dosage than with increasing ABF activity. Transformant N593: : pIM991-17 features a reduction intermediate between strains -135 and -121 while these three strains harbour similar amounts of additional abfB copies. N593::pIM991-17 is the most moderate overproducer of PNP-A hydrolysing activity, which could be due to abundant presence of nonfunctional $a b f B$ copies. This strongly suggests that extra $a b f$ copies titrate a common transcriptional activator. In abf $A$ transformants the repression never exceeds $50 \%$, while the ABN A expression level is reduced to $20-40 \%$ in the $a b f B$ multiple copy strains. This indicates that distinct factors are titrated by the respective $A B F$ encoding genes. Notably, the wild-type ABN level remains constant while in all transformants except N593:: pIM900-11, ABN expression increases with time.

To study the effect of additional abf gene copies on the expression of the individual $\mathrm{ABF}$, we investigated arabinase expression more directly at the level of transcription. The experiment was set up essentially as described previously (Flipphi et al., 1993 b; van der Veen et al., 1993), performing mycelial transfer of sucrosegrown biomass to minimal medium containing the simple and defined substrate L-arabitol as sole carbon source. In such an experiment expression of all three arabinases is accomplished, and their secretion reaches steady state levels within $6 \mathrm{~h}$ of transfer, without the lag phase characteristic for induction on sugar beet pulp upon mycelial transfer (unpublished results). Mycelium was recovered at 1,3 and $5 \mathrm{~h}$ after transfer. Biomass isolated $2 \mathrm{~h}$ after transfer to minimal medium containing $\mathrm{D}$ glucose, was used as a control for proper induction. Slot blot analysis of total RNA $(10 \mu \mathrm{g})$ revealed the presence of small amounts of $a b f A$ and $a b f B$ mRNA in D-glucose transferred mycelium of all strains (data not shown). This suggests low constitutive expression of both $\mathrm{ABF}$ encoding genes on D-glucose.

Slot blot analysis of the time course of induction (Fig. 4) clearly shows that $\mathrm{L}$-arabitol induces arabinase expression. The mRNA levels of the various transformant strains correlate with the overexpression of extracellular PNP-A hydrolysing activity (Table 2). The three genes studied respond differently on transfer to medium containing Larabitol. For $a b f A$, the expression levels were high $1 \mathrm{~h}$ after transfer and decreased with time. In contrast, $a b n A$ was hardly expressed after $1 \mathrm{~h}$ but the mRNA level sharply rose between 1 and $3 \mathrm{~h}$ after transfer. The $a b f B$ gene was clearly expressed after $1 \mathrm{~h}$ of induction and its expression level slowly increased with time. In all transformants, the presence of multiple copies of either $a b f$ gene led to a decrease of the expression level of $a b n A$ correlating with increasing gene dosage. This effect was most evident after $1 \mathrm{~h}$ but for the $a b f B$ transformants was also clear at both other time points. These data verify the activity measurements from the sugar beet pulp cultures, although repression of $A B N A$ expression is far more persistent on sugar beet pulp. The slot blots (Fig. 4) suggest that extra $a b f B$ copies affect $\mathrm{ABF}$ A expression, although there is no clear relationship between the reduction of the expression level and the $a b f B$ gene

marked $\$$. The $5^{\prime}$ ultimate base of the CDNA insert from pC2X1 (position 486) is marked $5^{\prime}$; the $3^{\prime}$ ultimate bases of the CDNA inserts from $p C 2 \times 1$ and $p C 1 \times 1$ are marked $43^{\prime}$. Putative promoter elements in the upstream non-coding sequence thought to effect transcription initiation are double underlined (TATA boxes/CT stretches). The CT-rich and GA-rich upstream sequences are marked by underlining. Various putative sequence elements are indicated by arrows either above or underneath the sequence, and marked with uppercase letters. A T-rich sequence found in the $3^{\prime}$ non-coding sequence is underlined. Determined amino acid sequences are underlined. Putative $\mathrm{N}$-glycosylation sites are indicated by double underlining. 


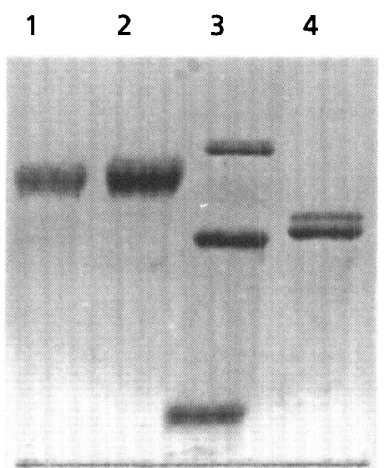

Fig. 3. SDS-PAGE analysis of deglycosylation of ABF $A$. Deglycosylation of $2 \mu \mathrm{g} \mathrm{ABF} \mathrm{A} \mathrm{was} \mathrm{performed} \mathrm{as} \mathrm{described} \mathrm{in}$ Methods. Loading buffer was applied to stop the reaction and half the volume of each sample $(20 \mu \mathrm{l})$ was directly applied on a $10 \%$ polyacrylamide gel. Lanes: 1 , untreated ABF A $(1 \mu \mathrm{g}) ; 2$, ABF $A$ incubated in the absence of $N$-glycanase; 3 , molecular mass markers (ovalbumin, $45 \mathrm{kDa}$; bovine serum albumin, $67 \mathrm{kDa}$; phosphorylase $B, 92.5 \mathrm{kDa}$ ); 4 , ABF $A$ incubated in the presence of $\mathrm{N}$-glycanase. The figure shows representative results for one of two independent experiments.

dosage. In case of $\mathrm{ABF} \mathrm{B}$ in $a b f A$ transformants, effects similar to those found for $A B N A$ were evident though far less pronounced. Expression of $a b f B$ was reduced in strains N593::pIM900-11 and -1, mainly at $1 \mathrm{~h}$ after transfer.

\section{DISCUSSION}

Previously we isolated and characterized two of the genes involved in L-arabinan degradation by $A$. niger, $a b f B$ and $a b n A$. In this paper the structure of a third gene involved, $a b f A$, and its gene product $\mathrm{ABF} \mathrm{A}$ are presented. The deduced amino acid sequences from the three $A$. niger arabinases do not exhibit sequence similarity, although all act on $(1 \rightarrow 5)-\alpha$-glycosidic linkages between L-arabinofuranosyl residues. Primary structure alignments indicate that none of the arabinases is related to any of the prokaryotic glycosyl hydrolases known to exhibit PNP-A hydrolysing or L-arabinose releasing activities. It seems likely that the arabinases represent a novel class of glycosyl hydrolase families, reflecting a specific architecture fitting the furanosyl configuration of $\mathrm{L}$-arabinose. Biochemically, a major difference between $\mathrm{ABF} A$ and the other two arabinases is that $\mathrm{ABF} A$ acts only on small oligomers; its activity was found to decrease progressively with increasing length of $(1 \rightarrow 5)$ - $\alpha$-linked oligomers (Rombouts et al., 1988). This coincides with the fact that ABF A is $N$ glycosylated while $\mathrm{ABF} \mathrm{B}$ and $\mathrm{ABN} \mathrm{A}$ are not. $\mathrm{N}$ glycanase does not affect the apparent molecular masses of $\mathrm{ABF} B$ and $\mathrm{ABN} A$ (results not shown), indicating that these glycoproteins are $O$-glycosylated. Morosoli et al. (1992) suggested that $N$-glycosylation affects the substrate specificity as well as the kinetic properties of a xylanase from the yeast Cryptococcus albidus. Unglycosylated xylanase, produced intracellularly by transformed E. coli, exhibited reduced substrate affinity while the substrate specificity was shifted from oligomers towards polymers.
However, $N$-linked glycosyl moieties in fungal extracellular enzymes are generally considered to be involved in protection against host-specific proteases and in heat stability, rather than in activity (cf. Tanner \& Lehle, 1987). One of the putative sites for $N$-glycosylation (Fig. 2 ) is located at position 12 of the determined N-terminal sequence of the internal $\mathrm{CNBr}$-generated peptide. Attachment of a glycosyl group to the asparagine on that position could be the reason that we were unable to assign this residue upon Edman degradation of the CNBrderived peptide. Enzymic deglycosylation not only reduces the apparent molecular mass, it also changes the appearance of ABF A upon SDS-PAGE from a broad diffuse band to a condensed sharp band (Fig. 3), indicating that the fuzzy appearance of purified (glycosylated) $\mathrm{ABF}$ A could well be a result of modifications of $N$-linked sugars.

Analysis of the $5^{\prime}$ non-coding sequence of the abf $A$ gene (Fig. 2) shows that the transcription initiation site (39 bp upstream of the start codon) is located 6 bases downstream of a $10 \mathrm{bp}$ long CT stretch, an element involved in initiation of transcription of several highly expressed fungal genes (cf. Gurr et al., 1987; Unkles, 1992). Further upstream two AT stretches TTAATTT ( -91 to -85 relative to the start codon) and ATAAAA ( -69 to -64$)$ are present, located such that these sequences could operate as functional TATA-elements. Upstream of the most distal TATA-like element, $a b f A$ is highly structured. A CT-rich area of $104 \mathrm{bp}(84.6 \% \mathrm{CT})$ is preceded by a $46 \mathrm{bp}$ GA-rich area $(82.6 \% \mathrm{GA})$ as reflected by the presence of a perfect $11 \mathrm{bp}$ long dyad symmetry (denoted $R$ in Fig. 2). The CT-rich area includes a complex $40 \mathrm{bp}$ region devoid of Gs exhibiting extensive internal homology, i.e. there are five perfect $5 \mathrm{bp}$ repeats (TCCAC) present. In Fig. 2 we indicated the internal homology by three $10 \mathrm{bp}$ direct repeats of the sequence $\mathrm{CT} /$ ACCTCCACA/T (element A) together with a truncated 6 bp copy TCCACA. The most distal copy of this element partly overlaps the most proximal half of the dyad symmetry element $R$. Recent studies indicated that all three arabinase genes are subjected to carbon catabolite repression by D-glucose (van der Veen et al., 1993). abf $A$ contains several sequence elements (marked C in Fig. 2) perfectly matching the consensus sequence of the cisacting element found in the $A$. nidulans alc $A$ and alcR genes (G/CC/TGGGG), involved in D-glucose-mediated carbon catabolite repression of the ethanol utilization regulon by the DNA-binding repressor protein CREA (Kulmburg et al., 1993). Several copies of this element are also present in $a b n A$ and $a b f B$ (Fig. 5).

The results indicate that regulation of arabinase synthesis exhibits coordinated features, which could be mediated through common cis-acting sequence elements. Comparing the sequences of the arabinase genes, several such elements were found (Fig. 5 ; see Fig. 2 for $a b f A$ ). Element $\mathrm{B}$ (TCCCTGAA) is present as a single copy in each gene, though several truncated and complementary versions are present in all genes. The core of this element (CCCTGA) is found in all pectinolytic $A$. niger genes of which sequences are available (Bussink et al., 1992). Element B 
Table 1. Conserved amino acid sequence elements found in ABFA and two Klebsiella pullulanases by primary structure alignment

\begin{tabular}{|c|c|c|c|}
\hline Protein* & $\begin{array}{c}\text { Residue } \\
\text { no.t }\end{array}$ & Amino acid sequence $\ddagger$ & $\begin{array}{l}\text { Sequence } \\
\text { element }\end{array}$ \\
\hline A. niger $\mathrm{ABF} \mathrm{A}$ & 209 & DMKGSFLRF & \\
\hline K. aerogenes PUL & 368 & DLKGAFYRY & Element e \\
\hline K. pneumoniae PUL & 358 & DLKGAFYRY & \\
\hline A. niger $\mathrm{ABF} \mathrm{A}$ & 270 & DIGLVPVLGV & \\
\hline \multirow[t]{2}{*}{ K. aerogenes $\mathrm{PUL}$} & 611 & DLGMNVIMDV & \\
\hline & 491 & IELLPVFDL & \\
\hline \multirow[t]{2}{*}{ K. pneumoniae PUL } & 601 & DLGMNVIMDV & \\
\hline & 481 & VELLPVFDL & \\
\hline A. niger $\mathrm{ABF} \mathrm{A}$ & 302 & IDDVLNEL & \\
\hline$K$. aerogenes PUL & 532 & VEEVLNQI & \\
\hline K. pneumoniae PUL & 531 & VEEVLNQL & \\
\hline A. niger $\mathrm{ABF} \mathrm{A}$ & 386 & SMPEGSWVDYHDY & \\
\hline \multirow[t]{3}{*}{$K$. aerogenes $\mathrm{PUL}$} & 582 & TVPEGSY & \\
\hline & 689 & DGFEREDLMGY & Element $g$ \\
\hline & 846 & YVSKHD & Element $\mathrm{j}$ \\
\hline \multirow[t]{3}{*}{ K. pneumoniae PUL } & 572 & TVPEGSY & \\
\hline & 679 & DGFRFDLMGY & \\
\hline & 836 & Y $\underline{\mathbf{V} S K H D}$ & \\
\hline A. niger ABF A & 427 & RWEIDWP-NLKGS & \\
\hline K. aerogenes PUL & 732 & RFEIASQINLKGT & \\
\hline K. pneumoniae PUL & 722 & REEIASQINLKGT & \\
\hline A. niger $\mathrm{ABF} \mathrm{A}$ & 475 & DIIGY & \\
\hline$K$. aerogenes $\mathrm{PUL}$ & 694 & DLMGY & \\
\hline K. pneumoniae PUL & 684 & DLMGY & \\
\hline A. niger $\mathrm{ABF} \mathrm{A}$ & 589 & TFSLPAWAVAVI & \\
\hline$K$. aerogenes PUL & 1072 & SVTLPAWSVAVI & \\
\hline K. pneumoniae PUL & 1062 & TVTLPAWSVAVI & \\
\hline
\end{tabular}

* K. aerogenes pullulanase (PUL A) (Katsuragi et al., 1987). K. pneumoniae pullulanase (PUL A) (Kornacker \& Pugsley, 1990).

† The residue numbers apply to the $\mathrm{N}$-terminal residue of the aligned sequences in the respective proteins. $\ddagger$ Identical amino acids are in bold face. Residues conserved amongst glycosyl hydrolases from family 13 are underlined.

$\S$ Sequence elements described by Melasniemi et al. (1990).

bears similarity to a cAMP responsive element $\left(\mathrm{UAS}_{\mathrm{PDS}}\right.$ ) in a yeast heat shock protein HSP70-encoding gene (TT/AAGGGAI), reported to mediate repression in the presence of fermentable carbon sources (Boorstein \& Craig, 1990). A single copy of element D (T/CGACA/ GTCA) is present in each gene and is highly similar to a cAMP responsive element (TGACGTCA) (CRE/ATF) found in mammalian genes, conferring both activating and repressing effects (e.g. Roesler et al., 1988). Element A (CT/ACCTCCACA/T), the repeated element in the upstream region of abf $A$ as discussed above, is found as a single copy in $a b n A$ and as a truncated copy (CACCTCCATT) in $a b f B$. No functional analogues could be found for this element but it is also present in the upstream non-coding region of a number of totally unrelated fungal genes, e.g. amongst others, Ascobolus immersus met2 (homoserine O-transacetylase) (Goyon et al., 1988), Neurospora crassa grg-1 (glucose repressible gene) (McNally \& Free, 1988) and Aspergillus awamori pby (phytase) (Mullaney et al., 1991) (data not shown). It seems likely that all the common sequence elements represent more general regulatory features. Whether these elements are actually involved in regulation of arabinase expression is under investigation.

Expression of arabinases in $A$. niger is inducible both by complex substrates containing $\mathrm{L}$-arabinan and by $\mathrm{L}$ arabitol. The two expression experiments described here were conducted under quite different experimental and physiological conditions. The different time scale and detection method chosen are a consequence of the totally distinct nature of the two compounds employed as 
Table 2. PNP-A hydrolysing activities and $A B N$ activities produced by $A$. niger wild-type and abf-transformed strains upon growth on sugar beet pulp

Transformed strains are ordered with increasing copy numbers as indicated by Southern blot analyses (not shown). Representative values from one of two independent experiments are given.

\begin{tabular}{|c|c|c|c|}
\hline $\begin{array}{l}\text { Time } \\
\text { point } \\
\text { (h) }\end{array}$ & Strain & $\begin{array}{c}\text { Relative } \\
\text { ABN } \\
\text { activity* }\end{array}$ & $\begin{array}{c}\text { Relative } \\
\text { PNP-A } \\
\text { activity }\end{array}$ \\
\hline \multirow[t]{9}{*}{24} & $\mathrm{~N} 402$ & $1 \cdot 00$ & $1 \cdot 00$ \\
\hline & N593::pIM900-4 & $0 \cdot 80$ & $1 \cdot 85$ \\
\hline & N593::pIM900-11 & 0.67 & $3 \cdot 00$ \\
\hline & N593::pIM900-1 & 0.53 & 6.83 \\
\hline & N593::pIM991-18 & $0 \cdot 41$ & $4 \cdot 25$ \\
\hline & N593::pIM991-135 & $0 \cdot 28$ & $5 \cdot 15$ \\
\hline & N593::pIM991-17 & $0 \cdot 29$ & $2 \cdot 37$ \\
\hline & N593::pIM991-121 & 0.34 & $7 \cdot 61$ \\
\hline & N593::pIM991-112 & $0 \cdot 18$ & $12 \cdot 44$ \\
\hline \multirow[t]{9}{*}{36} & N402 & $1 \cdot 00$ & $1 \cdot 00$ \\
\hline & N593::pIM900-4 & $0 \cdot 87$ & 1.87 \\
\hline & N593::pIM900-11 & $0 \cdot 61$ & 3.03 \\
\hline & N593::pIM900-1 & 0.51 & 6.43 \\
\hline & N593::pIM991-18 & $0 \cdot 42$ & 3.59 \\
\hline & N593::pIM991-135 & $0 \cdot 30$ & 4.97 \\
\hline & N593::pIM991-17 & 0.33 & $2 \cdot 14$ \\
\hline & N593::pIM991-121 & 0.35 & $6 \cdot 82$ \\
\hline & N593::pIM991-112 & $0 \cdot 21$ & $11 \cdot 17$ \\
\hline \multirow[t]{9}{*}{48} & N402 & $1 \cdot 00$ & $1 \cdot 00$ \\
\hline & N593::pIM900-4 & 0.92 & 1.88 \\
\hline & N593::pIM900-11 & 0.69 & $2 \cdot 99$ \\
\hline & N593::pIM900-1 & 0.58 & 6.31 \\
\hline & N593::pIM991-18 & $0 \cdot 45$ & $3 \cdot 50$ \\
\hline & N593::pIM991-135 & 0.33 & $4 \cdot 65$ \\
\hline & N593::pIM991-17 & $0 \cdot 34$ & $2 \cdot 06$ \\
\hline & N593::pIM991-121 & $0 \cdot 36$ & 6.35 \\
\hline & N593::pIM991-112 & $0 \cdot 22$ & $10 \cdot 51$ \\
\hline
\end{tabular}

* ABN activity was determined in duplicate, as described in Methods assaying $50 \mu \mathrm{l}$ of culture medium for $10 \mathrm{~min}$. Activities are given relative to the wild-type level at each consecutive time point. The wild-type level produced by $\mathrm{N} 402$ is 0.241 Units ml $^{-1}( \pm 0.004)$ at $24 \mathrm{~h}, 0.246$ Units $\mathrm{ml}^{-1}( \pm 0.008)$ at $36 \mathrm{~h}$ and 0.238 Units $\mathrm{ml}^{-1}$ $( \pm 0.008)$ at $48 \mathrm{~h}$.

† PNP-A hydrolysing activity was determined in quadruplicate, as described in Methods assaying $10 \mu \mathrm{l}$ of culture medium for $10 \mathrm{~min}$. Activities are given relative to the wild-type level at each consecutive time point. The wild-type level produced by N402 is 0.241 Units $\mathrm{ml}^{-1}( \pm 0.015)$ at $24 \mathrm{~h}, 0.301$ Units $\mathrm{ml}^{-1}( \pm 0.010)$ at $36 \mathrm{~h}$ and 0.342 Units $\mathrm{ml}^{-1}( \pm 0.013)$ at $48 \mathrm{~h}$.

inducing agents. Nevertheless, we found clear indications that additional copies of either $a b f$ gene influence the expression of $A B N A$ on sugar beet pulp and on $L$-arabitol similarly. In both experiments the influence of $a b f B$ is stronger than of $a b f A$. However, even in the case of the highest $a b f B$ gene dosage (strain N593::pIM991-112), ABN A expression still reaches $20 \%$ of the wild-type level (a)

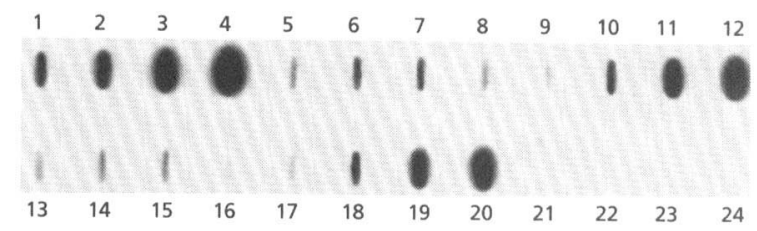

(b)

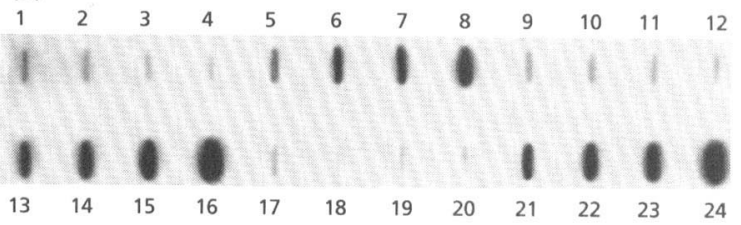

(c)

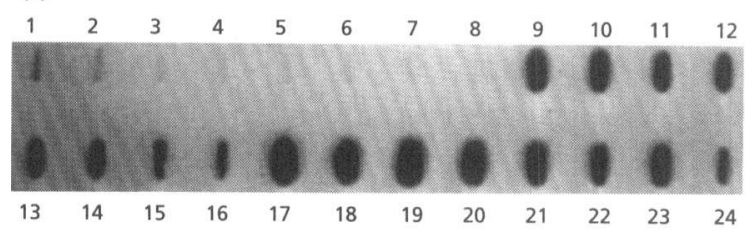

(d)

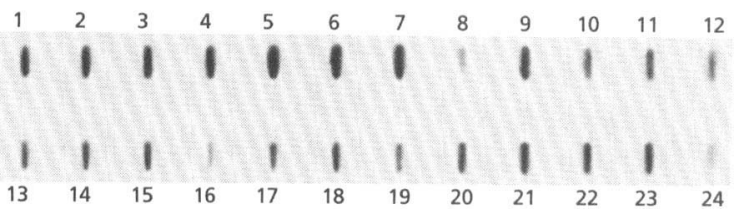

Fig. 4. Slot blot analysis of L-arabitol-induced arabinase expression by $A$. niger wild-type and abf transformed strains. Transformed strains are ordered with increasing copy numbers as indicated by Southern blot analyses (not shown). Each slot is loaded with $1 \mu \mathrm{g}$ of total RNA. (a) Blot probed with a $2.0 \mathrm{~kb}$ Pst fragment from pIM900, containing most of the coding area of the abfA gene (cf. Fig. 1). (b) Blot probed with a $2.8 \mathrm{~kb}$ Pstl fragment from plM991, containing the complete coding area of the abfB gene (Flipphi et al., 1993a). (c) Blot probed with the whole $3.1 \mathrm{~kb}$ Hindlil insert from plM950, carrying the $a b n A$ gene (Flipphi et al., 1993b). (d) Blot probed with a $830 \mathrm{bp}$ Ncol/Kpnl fragment from pSK5, containing mainly coding sequences from the heterologous $A$. nidulans $\gamma$-actin gene (Fidel et al., 1988). Slots: 1-8, N402, N593::plM900-4, $-11,-1$, N593::plM991-18, $-135,-121,-112$ (mycelium isolated $1 \mathrm{~h}$ after transfer); 9-16, ibid. (isolated $3 \mathrm{~h}$ after transfer); 17-24, ibid. (isolated $5 \mathrm{~h}$ after transfer). These blots show representative results from one out of two independent experiments and should not be used to compare the expression levels of the three arabinase genes, as the specific activity of the probes used was not determined.

on sugar beet pulp (Table 2). The effect of extra $a b f B$ copies is also more persistent than that of extra abf $A$ copies.

Extra copies of either abf gene seem to titrate distinct regulatory factors which could contribute to coordination of arabinase gene expression, especially with reference to $\mathrm{ABN}$ A. Another feature concerning ABN A expression was noticed previously (Flipphi et al., 1993b). In A. niger transformants carrying multiple copies of the $a b n A$ gene grown on sugar beet pulp, overexpression of ABN A did not exceed a limit of five times that of the wild-type level. 


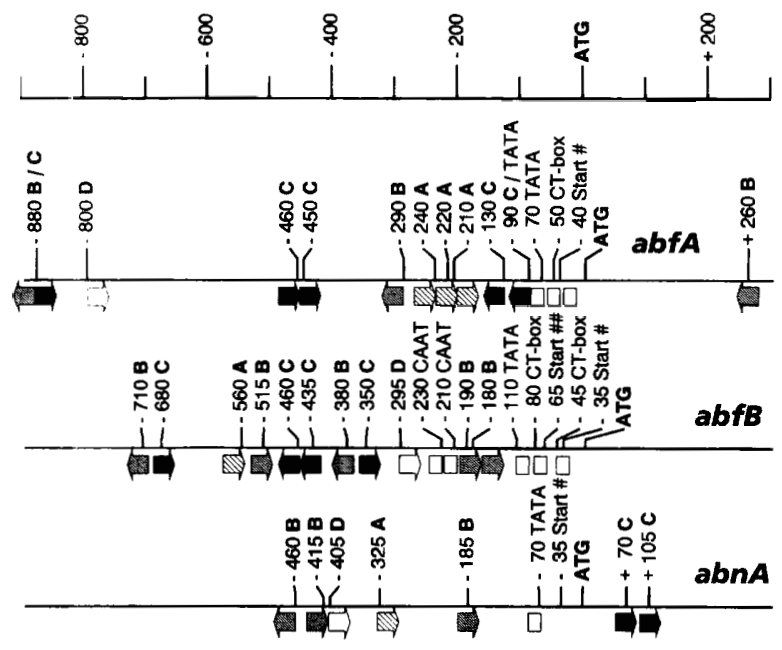

Fig. 5. Schematic overview showing the localization and orientation of common putative sequence elements in the $5^{\prime}$ regions ( -900 to +300 relative to the translation start codon ATG) of the $A$. niger arabinase genes ( $a b f A, a b f B$ and $a b n A$ ). The four different elements (A, B, C, D) are represented by distinct arrows and the approximate distances from the respective translation start codon (ATG) are indicated, as for the major transcription initiation sites of the respective genes. Sequences similar to functional general eukaryotic promoter elements (CAAT box, TATA box and CT stretch) are represented by open boxes. Only those putative CREA sites (C) are given which are found in conjunction with either another CREA site or with any other of the indicated elements.

The PNP-A hydrolysing activity was not affected in these transformants (unpublished results). This limitation does not occur in heterologous $A$. nidulans multiple copy transformants nor in case of the two abf genes (Flipphi et al., 1993a, c). Similar behaviour has been described in other fungal systems, e.g. cellobiohydrolase II ( $c b h 2$ gene) of Trichoderma reesei and alcohol dehydrogenase I (alc $A$ gene) of A. nidulans (Kubicek-Pranz et al., 1991 ; Gwynne et al., 1989). In the latter case this was due to limited expression of ALCR, the pathway-specific activator of the ethanol utilization regulon. In conclusion, the data presented suggest that at least three different activators, one titrated by multiple abf $A$ copies, one titrated by multiple $a b f B$ copies and an $a b n A$-specific one, are involved in ABN A expression. Moreover, arabinase expression seems to be co-regulated to some extent. The different behaviour of the three genes in wild-type and multiple copy transformants implies however that expression is basically governed by gene-specific factors, while cootdinated control is restricted merely to modulation of the expression level.

\section{ACKNOWLEDGEMENTS}

The authors wish to thank Sabine Cuypers for technical assistance and Dr Bernard Henrissat (CERMAV-CNRS, Grenoble, France) for his interest and help in connection with hydrophobic cluster analysis of ABF A. The presented work is part of a project granted by the Dutch committee for Agricultural Biotechnology (PcLB).

\section{REFERENCES}

Beldman, G., Searle-van Leeuwen, M. J. F., de Ruiter, G. A., Siliha, H. A. \& Voragen, A. G. J. (1993). Degradation of arabinans by arabinanases from Aspergillus aculeatus and Aspergillus niger. Carbobydr Polym 20, 159-168.

Boorstein, W. R. \& Craig, E. A. (1990). Regulation of a yeast HSP70 gene by a cAMP responsive transcriptional control clement. EMBO J 9, 2543-2553.

Bussink, H. J. D., Buxton, F. P., Fraaye, B. A., de Graaff, L. H. \& Visser, J. (1992). The polygalacturonases of Aspergillus niger are encoded by a family of diverged genes. Eur J Biochem 208, 83-90.

Calzone, F. J., Britten, R. J. \& Davidson, E. H. (1987). Mapping of gene transcripts by nuclease protection assays and $\mathrm{cDNA}$ primer extension. Methods Enzymol 152, 611-632.

Chirgwin, J. M., Przybyla, A. E., MacDonald, R. J. \& Rutter, W. J. (1979). Isolation of biologically active ribonucleic acid from sources enriched in ribonuclease. Biochemistry 18, 5294-5299.

Dente, L. \& Cortese, R. (1987). pEMBL: a new family of singlestranded plasmids for sequencing DNA. Methods Enzymol 155, 111-119.

Fidel, S., Doonan, J. H. \& Morris, N. R. (1988). Aspergillus nidulans contains a single actin gene which has unique intron locations and encodes a $\gamma$-actin. Gene 70, 283-293.

Flipphi, M. J. A., van Heuvel, M., van der Veen, P., Visser, J. \& de Graaff, L. H. (1993a). Cloning and characterization of the $a b f B$ gene coding for the major $\alpha$-L-arabinofuranosidase (ABF B) of Aspergillus niger. Curr Genet 24, 525-532.

Flipphi, M. J. A., Panneman, P., van der Veen, P., Visser, J. \& de Graaff, L. H. (1993b). Molecular cloning, expression and structure of the endo-1,5- $\alpha$-L-arabinase gene of Aspergillus niger. Appl Microbiol Biotecbnol 40, 318-326.

Flipphi, M. J. A., Visser, J., van der Veen, P. \& de Graaff, L. H. (1993c). Cloning of the Aspergillus niger gene encoding $\alpha-\mathrm{L}-$ arabinofuranosidase A. Appl Microbiol Biotechnol 39, 335-340.

Gaboriaud, C., Bissery, V., Benchetrit, T. \& Mornon, J. P. (1987). Hydrophobic cluster analysis: an efficient new way to compare and analyse amino acid sequences. FEBS Lett 224, 149-155.

Glišin, V., Crkvenjakov, R. \& Byus, C. (1974). Ribonucleic acid isolated by cesium chloride centrifugation. Biochemistry 13, 2633 2637.

Goyon, C., Faugeron, G. \& Rossignol, J.-L. (1988). Molecular cloning and characterization of the met 2 gene from Ascobolus immersus. Gene 63, 297-308.

de Graaff, L., van den Broek, H. \& Visser, J. (1988). Isolation and expression of the Aspergillus nidulans pyruvate kinase gene. Curr Genet 13, 315-321.

Gurr, S. J., Unkles, S. E. \& Kinghorn, J. R. (1987). The structure and organization of nuclear genes of filamentous fungi. In Gene Structure in Eukaryotic Microbes. SGM Special Publication. Vol. 23, pp. 93-139. Edited by J. R. Kinghorn. Oxford: IRL Press.

Gwynne, D. I., Buxton, F. P., Williams, S. A., Sills, A. M., Johnstone, J. A., Buch, J. K., Guo, Z.-M., Drake, D., Westphal, M. \& Davies, R. W. (1989). Development of an expression system in Aspergillus nidulans. Biochem Soc Trans 17, 338-340.

von Heijne, G. (1986). A new method for predicting signal sequence cleavage sites. Nucleic Acids Res 14, 4683-4691.

Henrissat, B. (1991). A classification of glycosyl hydrolases based on amino acid sequence similarities. Biochem $J$ 280, 309-316.

Hirani, S., Bernasconi, R. J. \& Rasmussen, J. R. (1987). Use of peptide- $N$-glycosidase $F$ to release asparagine-linked oligosaccharides for structural analysis. Anal Biochem 162, 485-492. 
Katsuragi, N., Takizawa, N. \& Murooka, Y. (1987). Entice nucleotide sequence of the pullulanase gene of Klebsiella aerogeries W70. J Bacteriol 160, 2301-2306.

Kellett, L. E., Poole, D. M., Ferreira, L. M. A., Durrant, A. J., Hazlewood, G. P. \& Gilbert, H. J. (1990). Xylanase B and an arabinofuranosidase from Pseudomonas fluorescens subsp. cellulosa contain identical cellulose-binding domains and are encoded by adjacent genes. Biochem J 272, 369-376.

Kormelink, F. J. M., Gruppen, H. \& Voragen, A. G. J. (1993). Mode of action of $(1 \rightarrow 4)-\beta$-D-arabinoxylan arabinofuranohydrolase $(\mathrm{AXH})$ and $\alpha$-L-arabinofuranosidases on alkali-extractable whestflour arabinoxylan. Carbobydr Res 249, 345-353.

Kornacker, M. G. \& Pugsley, A. P. (1989). Molecular characterization of pul $A$ and its product, pullulanase, a secreted enzyme of Klebsiella pneumoniae UNF5023. Mol Microbiol 4, 73-85.

Kubicek-Pranz, E. M., Gruber, F. \& Kubicek, C. P. (1991). Transformation of Trichoderma reesei with the cellobiohydrolase II gene as a means for obtaining strains with increased cellulase production and specific activity. $J$ Biotechnol 20, 83-94.

Kulmburg, P., Mathieu, M., Dowzer, C., Kelly, J. \& Felenbok, B. (1993). Specific binding sites in the alc $\mathrm{R}$ and alc $A$ promoters of the ethanol regulon for the CREA repressor mediating carbon catabolite repression in Aspergillus nidulans. Mol Microbiol 7 , $847-857$

Laemmli, U. K. (1970). Cleavage of structural proteins during the assembly of the head of bacteriophage T4. Nature 227, 680-685.

Lerouge, P., O'Neill, M. A., Darvill, A. G. \& Albersheim, P. (1993). Structural characterization of endo-glycanase-generated oligoglycosyl side chains of rhamnogalacturonan I. Carbobydr Res 243, 359-371.

McCleary, B. V. (1991). Comparison of endolytic hydrolases that depolymerize 1,4- $\beta$-D-mannan, 1,5- $\alpha$-L-arabinan and 1,4- $\beta$-D-galactan. In Enzymes in Biomass Conversion. ACS Symposium Series 460, pp. 437-449. Edited by G. F. Leatham \& M. E. Himmel. Washington DC: American Chemical Society.

McMaster, G. K. \& Carmichael, G. G. (1977). Analysis of singleand double-stranded nucleic acids on polyacrylamide and agarose gels by using glyoxal and acridine orange. Proc Natl Acad Sci US A 74, 4835-4838.

McNally, M. T. \& Free, S. J. (1988). Isolation and characterization of a Neurospora glucose-repressible gene. Curr Genet 14, 545-551.

Melasniemi, H., Paloheimo, M. \& Hemiö, L. (1990). Nucleotide sequence of the $\alpha$-amylase-pullulanase gene from Clostridium thermobydrosulfuricum. J Gen Microbiol 136, 447-454.

Morosoli, R., Durand, S. \& Moreau, A. (1992). Cloning and expression in Escherichia coli of a xylanase-encoding gene from the yeast Cryptococcus albidus. Gene 117, 145-150.

Mullaney, E. J., Gibson, D. M. \& Ullah, A. H. (1991). Positive identification of a $\lambda \mathrm{gt} 11$ clone containing a region of fungal phytase gene by immunoprobe and sequence verification. Appl Microbiol Biotechnol 35, 611-614.

Nishitani, K. \& Nevins, D. J. (1989). Enzymic analysis of feruloylated arabinoxylans (feraxan) derived from Zea mays cell walls. II. Fractionation and partial characterization of feraxan fragments dissociated by a Bacillus subtilis enzyme (feraxanase). Plant Pbysiol 91 , 242-248.

Rambosek, J. \& Leach, J. (1987). Recombinant DNA in filamentous fungi: progress and prospects. CRC Crit Rev Biotechnol 6, 357-393.

Roesler, W. J. Vanderbark, G. R. \& Hanson, R. W. (1988). Cyclic $\mathrm{AMP}$ and the induction of eukaryotic gene transcription. J Biol Chem 263, 9063-9066.
Rombouts, F. M., Voragen, A. G. J., Searle-van Leeuwen, M. F., Geraerds, C. C. J. M., Schols, H. A. \& Pilnik, W. (1988). The arabinanases of Aspergillus nigeri - purification and characterisation of two $\alpha$-L-arabinofuranosidases and an endo-1,5- $\alpha$-L-arabinanase. Carbobydr Polym 9, 25-47.

Sakai, T. \& Sakamoto, T. (1990). Purification and some properties of a protopectin-solubilizing enzyme that has potent activity on sugar beet protopectin. Agric Biol Chem 54, 879-889.

Sakka, K., Yoshikawa, K., Kojima, Y., Karita, S.-I., Ohmiya, K. \& Shimada, K. (1993). Nucleotide sequence of the Clostridium stercorarium $x y l A$ gene encoding a bifunctional protein with $\beta$-Dxylosidase and $\alpha$-L-arabinofuranosidase activities, and properties of the translated product. Biosci Biotech Biochem 57, 268-272.

Sambrook, J., Fritsch, E. F. \& Maniatis, T. (1989). Molecular Cloning : a Laboratory Manual, 2nd edn. Cold Spring Harbor, NY: Cold Spring Harbor Laboratory.

Sanger, F., Nicklen, S. \& Coulson, A. R. (1977). DNA sequencing with chain-terminating inhibitors. Proc Natl Acad Sci USA 74, 5463-5467.

Tanner, W. \& Lehle, L. (1987). Protein glycosylation in yeast. Biochim Biopbys Acta 906, 81-99.

Tarentino, A. L. \& Plummer, T. H., Jr (1987). Peptide- $N$-( $N$-acetyl$\beta$-glucosamidyl) asparagine amidase and endo- $\beta$ - $N$-acetylglucosaminidase from Flavobacterium meningosepticum. Methods Enzymol 138, 770-778.

Unkles, S. E. (1992). Gene organization in industrial filamentous fungi. In Applied Molecular Genetics of Filamentous Fungi. 1st edn, pp. 28-53. Edited by J. R. Kinghorn \& G. Turner. London: Blackie Academic \& Professional.

Utt, E. A., Eddy, C. K., Keshav, K. F. \& Ingram, L. O. (1991). Sequencing and expression of the Butyrivibrio fibrisolvens $x y / B$ gene encoding a novel bifunctional protein with $\beta$-D-xylosidase and $\alpha$-Larabinofuranosidase activities. Appl Environ Microbiol 57, $1227-$ 1234.

van der Veen, P., Flipphi, M. J. A., Voragen, A. G. J. \& Visser, J. (1991). Induction, purification and characterisation of arabinases produced by Aspergillus niger. Arch Microbiol 157, 23-28.

van der Veen, P., Flipphi, M. J. A., Voragen, A. G. J. \& Visser, J. (1993). Induction of extracellular arabinases on monomeric substrates in Aspergillus niger. Arch Microbiol 159, 66-71.

van de Vis, J. W., Searle-van Leeuwen, M. F., Siliha, H. A., Kormelink, F. J. M. \& Voragen, A. G. J. (1991). Purification and characterization of endo-1,4- $\beta$-D-galactanases from Aspergillus niger and Aspergillus aculeatus: use in combination with arabinanases from Aspergillus niger in enzymatic conversion of potato arabinogalactan. Carbobydr Polym 16, 167-187.

Voragen, A. G. J., Rombouts, F. M., Searle-van Leeuwen, M. F., Schols, H. A. \& Pilnik, W. (1987). The degradation of arabinans by endo-arabinanase and arabinofuranosidases purified from Aspergillus niger. Food Hydrocoll 1, 423-437.

Whitaker, J. R. (1984). Pectic substances, pectic enzymes and haze formation in fruit juices. Enzyme Microb Technol 6, 425-432.

Will, F. \& Dietrich, H. (1992). Isolation, purification and characterization of neutral polysaccharides from extracted apple juices. Carbobydr Polym 18, 109-117.

Witteveen, C. F. B., Busink, R., van de Vondervoort, P., Dijkema, C., Swart, K. \& Visser, J. (1989). L-Arabinose and D-xylose catabolism in Aspergillus niger. J Gen Microbiol 135, 2163-2171.

Received 11 April 1994; revised 3 June 1994; accepted 14 June 1994 